\title{
Reduced sinus arrhythmia in diabetic autonomic neuropathy: diagnostic value of an age-related normal range
}

\author{
SHIRLEY A SMITH
}

\begin{abstract}
A study was carried out to establish a normal range for use in a deep breathing test of cardiac vagal integrity in diabetes mellitus. The change in heart rate resulting from taking a deep breath was recorded in 174 healthy subjects aged 16-89 years. Results were expressed as the ratio of the longest $R-R$ interval during expiration to the shortest $R-R$ interval during inspiration. This ratio declined appreciably with age $(p<0.001)$ but was not significantly related to resting heart rate. An age-related normal range was constructed and its diagnostic value investigated in 134 diabetics (aged 15-70 years) with various degrees of neuropathy. The sensitivity for indicating autonomic dysfunction was high: six falsenegative and one false-positive result were obtained.

Measurement of this age-dependent ratio, which may be made with any electrocardiographic apparatus, provides a simple, accurate diagnostic screen for autonomic neuropathy in the clinic.
\end{abstract}

\section{Introduction}

Variations in heart rate in response to various stimuli, such as changes in posture or during deep breathing, are reduced in diabetic autonomic neuropathy. ${ }^{12}$ Measurement of the loss of these variations is widely used in diagnostic tests of this condition. ${ }^{3}$ Reduced sinus arrhythmia at rest and during forced breathing appears to reflect cardiac vagal dysfunction since the normal response is abolished by atropine and unaffected by propranolol. ${ }^{4}$ Age also reduces the amplitude of sinus arrhythmia, ${ }^{56}$ and allowance for this must be made in diagnostic tests of autonomic dysfunction. This study was done to establish an

Department of Pharmacology, St Thomas's Hospital Medical School, London SE1 7EH

SHIRLEY A SMITH, MA, PHD, honorary lecturer age-related normal range for results of a single deep breath test of sinus arrhythmia that can be measured direct from an electrocardiogram.

\section{Subjects and methods}

Tests were performed on 174 healthy subjects (aged 16-89 years) and 134 diabetics (aged 15-70 years) of both sexes. None was taking drugs known to interfere with cardiac function.

The diabetic patients were classified into four groups according to the severity of their neuropathy assessed by the following tests.

Tests of peripheral somatic nerve function-Thresholds of vibration sense were measured at the tips of the great toes and over the medial malleoli with a Bio-Thesiometer. ${ }^{7}$ Three estimates of the threshold were obtained at each of the four sites. The Bio-Thesiometer was applied gently to the skin and the amplitude of the vibration increased slowly until the patient first perceived vibration. The first estimate was discarded and the latter two averaged to give the threshold. A raised threshold was identified by comparing the result with the agerelated normal range established previously in this laboratory. Ankle and knee jerks were also examined: these were considered to be abnormal if any one was minimal or absent on reinforcement.

Tests of autonomic nerve function-Two types of test were usednamely, pupillary and cardiac. Previous studies in this laboratory have shown that abnormalities in these two systems correlate closely in diabetic autonomic neuropathy. ${ }^{78}$ Vertical pupillary diameters were measured in darkness and during stimulation with a flashlight by an infrared television system. Abnormalities in pupillary innervation were identified as a failure of dilatation in darkness and constriction to light using the laboratory's normal ranges. ${ }^{7}$ Cardiac beat-tobeat variation was measured using an electrocardiograph coupled to a Commodore Pet microcomputer as described elsewhere. ${ }^{5}$ Variations at rest and in response to five successive deep breaths and to a Valsalva manoeuvre were measured. Abnormally reduced variations for the patient's age and heart rate were identified by comparison with the laboratory's normal ranges. ${ }^{5}$

A careful history of any symptoms of autonomic neuropathy was taken; those regarded as important were postural hypotension, defined as postural symptoms with a fall in systolic pressure of $10 \mathrm{~mm} \mathrm{Hg}$ or more after a slow tilt to $70^{\circ}$ upright; diarrhoea of the typical periodic pattern with nocturnal bouts and episodes of faecal incontinence; and bladder atony, characterised by infrequent emptying and accompanied by palpable, painless distension of the bladder.

Using the results of the above tests the patients were classified as 
follows: group $0(n=17)$, those in whom all test results were normal; group $1(n=58)$, patients with peripheral somatic neuropathy-that is, vibration sense or knee and ankle jerks abnormal, all tests of autonomic function normal ; group $2(n=47)$, patients with autonomic dysfunction-that is, pupillary function or any test of cardiac autonomic function abnormal; and grade $3(n=12)$, patients with symptomatic autonomic neuropathy.

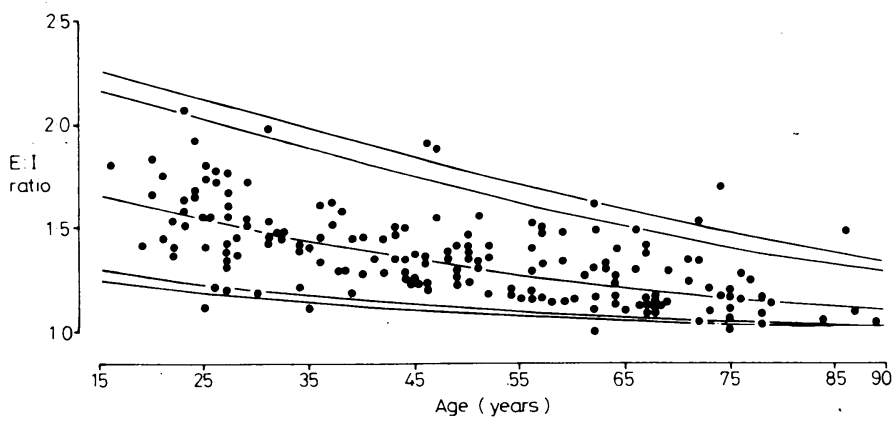

FIG 1 -Decline of the E:I ratio with age in 174 healthy subjects. The lines show the upper and lower 90th and 95th percentiles about the line of best fit, determined using the transformation described in the Results. The lower limit excludes four subjects $(2 \cdot 3 \%)$. distribution on age from which a normal range could be derived. The repeatability of the E:I ratio was assessed in 20 diabetic and 20 healthy subjects tested on two separate visits, the coefficient of variation of the within-subject variance being calculated. Both a digital-output electrocardiograph and the conventional paper-trace electrocardiograph were used for this analysis.

\section{Results}

The E:I ratio was found to decrease significantly with age $(p<0.001$; fig 1). There was no significant relation with resting heart rate (range 54-92 beats/min). To obtain a normal distribution of the ratios on age the data were transformed according to $0.5 \times(\log (\mathrm{E}: \mathrm{I}-1)-\log$ $(3-\mathrm{E}: \mathrm{I})$ ). This transformation is analogous to the $\mathrm{Z}$ transformation of the correlation coefficient $(r)$ in simple linear regression analysis. ${ }^{10}$ A plot of the transformed ratios on age was linear, allowing the 90th and 95th percentiles to be calculated by linear regression analysis. This transformation has no biological importance: it was done to obtain a statistically relevant normal range. Translating back from the transformation yielded. the normal range shown in figure 1. Ratios below the lower 95th percentile are abnormal; those between the 90th and 95 th are considered to be borderline. The table shows the ranges for five-year age groups.

Measurement of the $\mathrm{E}: \mathrm{I}$ ratio proved to be a sensitive test for autonomic neuropathy when used in conjunction with the normal range (fig 2 ). The ratios declined with increasing severity of neuro-
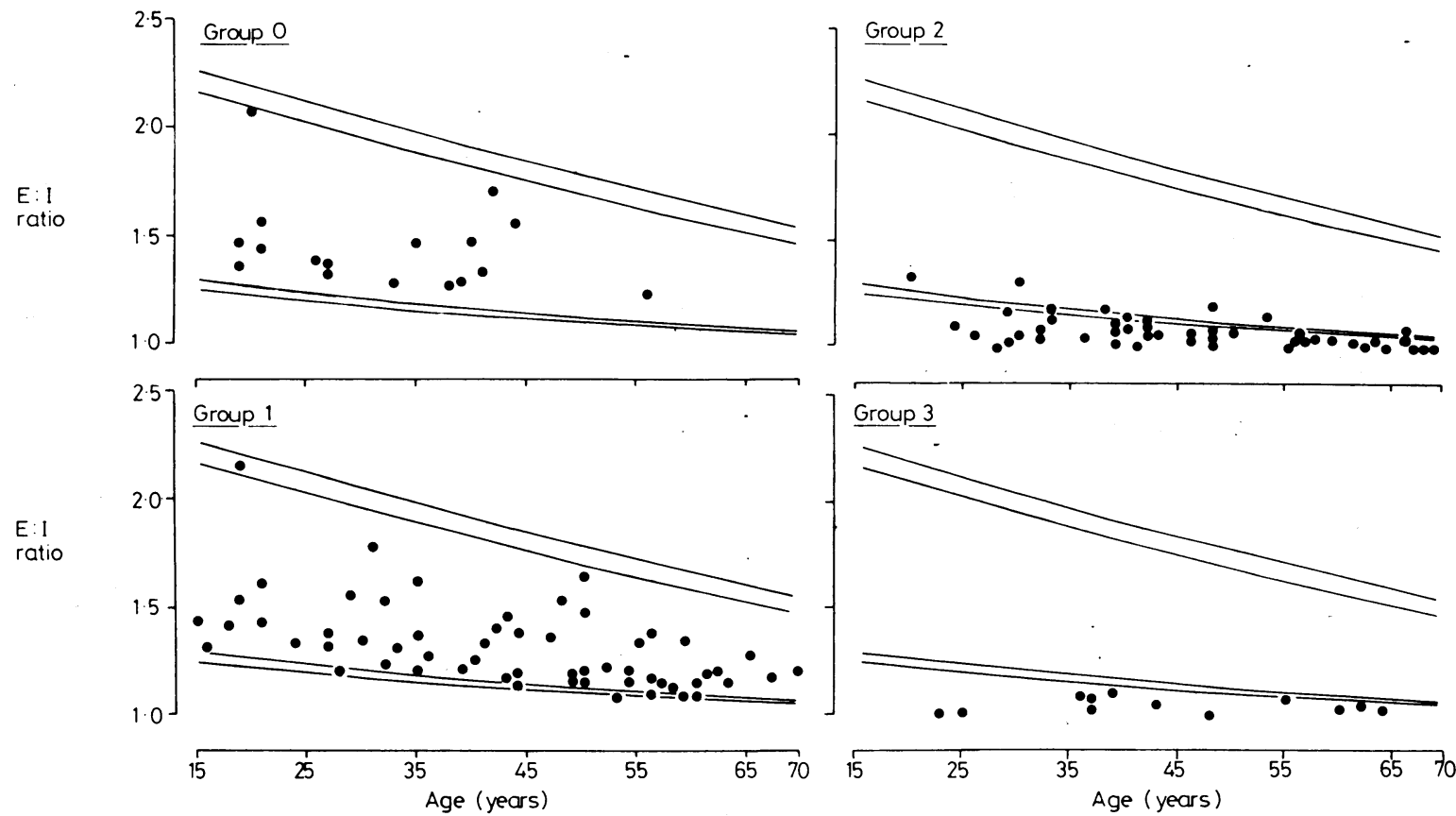

FIG 2-E:I ratio in the four groups of diabetics classified according to their neuropathic state. Test gave one false-positive result (in group 1) and six false-negative results (in group 2).

Single breath test-Sinus arrhythmia resulting from a single forced respiratory cycle was measured in all the healthy and diabetic subjects. With the subject supine an electrocardiogram was recorded in lead II and displayed either in conventional form on paper, run at a speed of $50 \mathrm{~mm} / \mathrm{s}$, or in digital form on the microcomputer as a sequence of beat-to-beat intervals. In the former case the intervals were measured from the paper with a ruler to the nearest $0.5 \mathrm{~mm}$ (or $10 \mathrm{~ms}$ ) and in the latter the measurement was made automatically to the nearest $5 \mathrm{~ms}$. The technician first demonstrated a single maximal deep breath lasting approximately $5 \mathrm{~s}$ in, $5 \mathrm{~s}$ out. The recording was then started and the subject instructed when to breath in and out. The shortest $R-R$ interval during inspiration (I) and the longest during expiration (E) were measured and the $\mathrm{E}: \mathrm{I}$ ratio calculated.

Statistical analysis-The ratios obtained in the healthy subjects were assessed for dependence on age and resting heart rate by multiple regression analysis. The data were then fitted to various mathematical models using the computer program GLIM $^{9}$ to obtain a normal
Age-related normal range for $E: I$ ratio from single breath test

\begin{tabular}{cccccc}
\hline $\begin{array}{c}\text { Age } \\
\text { (years) }\end{array}$ & $\begin{array}{c}\text { Lower 95th } \\
\text { percentile }\end{array}$ & $\begin{array}{c}\text { Lower 90th } \\
\text { percentile }\end{array}$ & $\begin{array}{c}\text { E:I } \\
\text { ratio }\end{array}$ & $\begin{array}{c}\text { Upper 90th } \\
\text { percentile }\end{array}$ & $\begin{array}{c}\text { Upper 95th } \\
\text { percentile }\end{array}$ \\
\hline $16-20$ & 1.23 & 1.27 & 1.62 & 2.13 & 2.22 \\
$21-25$ & 1.20 & 1.24 & 1.56 & 2.06 & 2.16 \\
$26-30$ & 1.18 & 1.22 & 1.51 & 1.99 & 2.09 \\
31.35 & 1.16 & 1.19 & 1.46 & 1.92 & 2.02 \\
$36-40$ & 1.14 & 1.17 & 1.41 & 1.85 & 1.95 \\
$41-45$ & 1.12 & 1.15 & 1.37 & 1.78 & 1.88 \\
$46-50$ & 1.11 & 1.13 & 1.33 & 1.72 & 1.81 \\
$51-55$ & 1.09 & 1.11 & 1.29 & 1.66 & 1.75 \\
$56-60$ & 1.08 & 1.10 & 1.26 & 1.60 & 1.68 \\
$61-65$ & 1.07 & 1.09 & 1.23 & 1.54 & 1.62 \\
$66-70$ & 1.06 & 1.08 & 1.20 & 1.49 & 1.57 \\
$71-75$ & 1.06 & 1.07 & 1.18 & 1.44 & 1.51 \\
$76-80$ & 1.05 & 1.06 & 1.16 & 1.40 & 1.46 \\
& & & & &
\end{tabular}

Values below lower 95th percentile are abnormal; those between 90th and 95th percentile are borderline. 
pathy. Only one abnormal ratio was found in the 75 diabetics of grades 0 and 1 , in whom autonomic function was normal on conventional testing. In grade 2,41 of the 47 diabetics gave abnormal or borderline results. The ratios in the 12 with symptomatic autonomic neuropathy (grade 3 ) were all well below the normal range.

Repeat measurements of the E:I ratio varied little; the coefficients of variation were $8.9 \%$ in healthy subjects and $5.3 \%$ in diabetics.

\section{Discussion}

Measurement of variation in heart rate during deep breathing is generally agreed to be a sensitive index of autonomic dysfunction, comparing favourably with tests based on changes in posture. ${ }^{13}$ Adaptation of a repeated deep breathing test for use with a conventional electrocardiogram to obtain an $\mathrm{E}: \mathrm{I}$ ratio was first described by Sundkvist et al, ${ }^{11}$ which represented a considerable simplification in technique over previous methods. These authors did not define the influence of age on this ratio but set the lower limit of normal at an E:I ratio of $1 \cdot 1$. When applied to the ratios measured here this limit gave three falsepositive and 16 false-negative diagnoses. The age-related normal range described in this report increases the diagnostic value of the $E$ :I ratio test since there were only one false-positive and six false-negative results.

There does not appear to be any advantage in averaging the variations in heart rate from a sequence of forced respirations compared with measuring the change resulting from a single deep breath. The change in rate is greater on the first breath ${ }^{12}$ and, in contrast to the mean, is not affected by the resting heart rate, ${ }^{5}$ which simplifies the construction of a normal range.

I conclude, therefore, that the E:I ratio test of sinus arrhythmia is an accurate and reliable method of screening diabetic patients for autonomic dysfunction. It may be performed rapidly by a nurse or technician with any electrocardio- graphic apparatus and immediate reference made to the normal range. It is thus appropriate for use in the diabetic clinic.

I am grateful to the British Diabetic Association for financial support, Professor S E Smith for statistical advice, and Professor P H Sönksen and Dr C Lowy for allowing me to study their patients.

\section{References}

1 Mackay JD, Page MMcB, Cambridge J, Watkins PJ. Diabetic autonomic neuropathy. The diagnostic value of heart rate monitoring. Diabetologia $1980 ; 18: 471-8$.

${ }^{2}$ Ewing DJ, Borsey DQ, Bellavere F, Clarke BF. Cardiac autonomic neuropathy in diabetes: comparison of measures of $R-R$ interval variation. Diabetologia $1981 ; 21: 18-24$.

${ }^{3}$ Anonymous. Diagnosis of autonomic neuropathy. (Editorial.) $\mathrm{Br} \mathrm{Med} \mathfrak{F}$ 1978;ii:910-1.

4 Wheeler T, Watkins PJ. Cardiac denervation in diabetes. $\mathrm{Br}$ Med $\mathcal{F}$ 1973; iv :584-6.

5 Smith SE, Smith SA. Heart rate variability in healthy subjects measured with a bedside computer-based technique. Clin Sci 1981;61:379-83.

6 Wieling W, van Brederode JFM, de Rijk LG, Borst C, Dunning AJ. Reflex control of heart rate in normal subjects in relation to age: a data base for cardiac vagal neuropathy. Diabetologia 1982;22:163-6.

7 Smith SE, Smith SA, Brown PM, Fox C, Sönksen P. Pupillary signs in diabetic autonomic neuropathy. $\mathrm{Br}$ Med F 1978;ii:924-7.

${ }^{8}$ Smith SA, Smith SE. Evidence for a neuropathic aetiology in the small pupil of diabetes mellitus. Br $\mathcal{F}$ Ophthalmol (in press).

${ }^{9}$ Baker RT, Nelder JA. The GLIM system manual for release 3. Oxford: Numerical Algorithms Group, 1978.

10 Fisher RA. Intraclass correlations. In: Statistical methods for research workers. 14th ed. Edinburgh: Oliver and Boyd, 1970:217-49.

11 Sundkvist G, Almer L-O, Lilja B. Respiratory influence on heart rate in diabetes mellitus. $\mathrm{Br}$ Med $\mathcal{F} 1979 ; \mathrm{i}: 924-5$.

12 Bennett T, Farquhar IK, Hosking DJ, Hampton JR. Assessment of methods for estimating autonomic nervous control of the heart in patients with diabetes mellitus. Diabetes 1978;27:1167-74.

(Accepted 16 September 1982) 